\title{
Health burden of urban transport: The technical challenge
}

\author{
CARLOS DORA
}

Sustainable Development and Healthy Environments, World Health Organization, CH-1211, Geneva 27

e-mail: dorac@who.int

\begin{abstract}
The burden on health-related issues due to unplanned urban policies is higher despite the present knowledge of interventions and availability of current technologies. This burden could increase substantially, given the rapid growth in urban populations and the application of partial or misguided solutions to urban transport problems. Part of the reason is the failure to consider holistically the health, social and environment consequences and the related costs of individual travel choices and government policies in the field of traffic and mobility. Urban transport-related issues and its impact on health, environment, costs and benefits are discussed in this paper.
\end{abstract}

Keywords. Public health; urban transport policies; transport problems; urban transport planning.

\section{Introduction}

Urban transportation is a major public health issue worldwide. Questions such as what modes of transport do people use everyday, how long and how often people travel are factors that have major implications for the health of individuals and of the population as a whole (British Medical Association, 1997). Urban transport-related activities have both negative and positive impact on health and transport policies are now a key determinant of health. The problem of health has therefore to be included on the transport and land use policy agenda to achieve health benefits. Transportation professionals have a key role to play in the health and wellbeing of communities.

Engineering works in the $19^{\text {th }}$ century led to major public health gains in urban areas, through water, sewage and housing improvements. The challenge at the beginning of this century is to plan and implement land use patterns and transport systems that avoid traffic injuries, air and noise pollution and, promote safe physical activity and social inclusion.

This paper summarizes the impact of urban transport on public health and emphasizes the urgent need to promote better health through transport-related issues in view of the increase in motor vehicles and populations in urban areas by identifying ways to facilitate the integration of public health and transportation. Issues that need specific attention for the development of healthy transport in emerging economies are identified. Engineers should take up this challenge and play their role in international public health. 


\section{Burden of disease from transport}

Current transport policies are a key determinant of the global burden of disease (WHO 2002); road traffic crashes cause 1.2 million deaths worldwide and urban air pollution is estimated to cause around 800 thousand deaths in urban areas every year (65\% of which are in Asia). Urban transport is also a root cause of physical inactivity (which causes 1.9 million deaths every year), of noise pollution, of climate change and issues related to psycho-social wellbeing. The evidence for these impacts is summarized below.

\subsection{Air pollution}

Transport-related air pollution is associated with short-term and long-term increases in ill health and mortality (Krzyzanowski et al 2005), including cardiovascular diseases (ischaemic heart disease, cerebrovascular disease, hypertensive disease, inflammatory heart disease), respiratory diseases (COPD, asthma, others), upper and lower respiratory infections, and lung cancer (Cohen et al 2004).

These health hazards can be attributed to a mixture of pollutants. Particles with less than 10 or $2.5 \mu$ in diameter (PM 10 and PM 2.5) are a good indicator of the air pollution mix that people are exposed to. Smaller particles can reach deep into lungs. Particles emitted by road vehicles consist of carbon, heavy metals and carcinogens such as benzene. Diesel vehicles are usually responsible for a large share of particles emissions.

Increasing concentrations of Particulate Matters (PM) can cause negative impact on health; the effect is stronger for PM $2 \cdot 5$, the particles coming from combustion engines, with a $3.4 \%$ increase in mortality for every $10 \mathrm{mg} / \mathrm{m}^{3}$ of PM 2.5 and $0.6 \%$ increase for PM 10 (Schwartz et al 2002).

No threshold could be identified below which health effects were not found, even for concentrations as low as $8 \mathrm{mg} / \mathrm{m}^{3}$ for PM 2.5 and $15 \mathrm{mg} / \mathrm{m}^{3}$ for PM 10 . To facilitate air quality management, some countries and regions have adopted limit values of 40 or $50 \mathrm{mg} / \mathrm{m}^{3}$ of PM 10 annual average.

Studies of health impacts of air pollution carried out outside Europe and USA show around a $1 \%$ increase in short-term mortality for a $10 \mathrm{mg} / \mathrm{m}^{3}$ increase in PM 10 . For example, cities with levels of $150 \mathrm{mg} / \mathrm{m}^{3}$ of PM 10, of which there are several in the developing world, would have a daily mortality rate $10 \%$ higher than cities with $20 \mathrm{mg} / \mathrm{m}^{3}$ levels of PM 10 .

Small particles can get indoors freely and can travel long distances across national boundaries, so neither the indoor environment nor distance from roads offers much protection against PM.

Other measures of exposure to air pollutants such as residences in close proximity to busy roads, or self-reported traffic intensity at a residence were associated with severe health hazards (Roemer \& van Wijnen 2001; Hoek et al 2002).

A large proportion of air pollution emissions is attributed to transport, especially in urban areas with large volumes of road traffic (EEA 2002). An even higher proportion of exposure to air pollution may be due to transport as air pollutants are concentrated in the immediate vicinity of (up to $250 \mathrm{~m}$ away from) urban highways, and in street canyons (Buringh et al 2002). In addition, levels of air pollutants in vehicles (underground trains, cars, and to a lesser extent buses) are up to a few times higher than what cyclists or pedestrians face on the same street/area (Sanderson et al 2005). Journey time exposures contribute disproportionately to total exposure, as people may spend hours commuting every day.

Health effects of air pollution observed in epidemiological studies seem to be greater in lower socio-economic groups (Pope et al 2002). One reason for this phenomenon may be 
cumulative factors increasing the chances for personal exposures and/or greater personal susceptibility in lower socio-economic groups (O'Neill et al 2003).

Reduction in air pollution has been quickly followed by reductions in mortality, as observed in Dublin (Clancy et al 2002) and Hong Kong (Hedley et al 2002). These observations are consistent with time series studies (showing that daily variation in health status of the population follows changes in air pollution) as well as with a study in California indicating improvement in lung function development in children moving to less polluted areas and worsening lung function development among children moving to more polluted areas (Avol et al 2001).

\subsection{Climate change}

Transport sector is one of the leading contributors to green house gases (GHG); in 1990 it produced $13 \%$ of global GHG emissions and the total contribution is expected to be more than double by 2020 (IPCC 2001a). Burning of fossil fuels over the last 50 years has produced sufficient quantities of GHG to affect the global climate. The global average temperature increased by around $0 \cdot 6^{\circ} \mathrm{C}$ over the last century and is expected to go up by between 1.4 and $5.6^{\circ} \mathrm{C}$ over this century (IPCC 2001b). The impact of climate change on health is mostly negative and expected to hit hardest those belonging to poorer communities who in fact contribute the least to climate change (McMichael \& Githeko 2001). Health impacts from climate change are expected through extreme weather events especially heat waves, leading to flood and drought. Changes in rainfall affect the supply of fresh water and increase the risk of water-borne diseases; together with higher temperatures this change affects food production, increasing the risks of malnutrition. Vector-borne diseases may affect regions without population immunity; in view of the changes in the length of transmission and the altered geographical range, the sea level rise will affect coastal areas and small islands (McMichael et al 2004). The International Panel on Climate Change (IPCC) considers that transport is also a sector where major opportunities exist for climate change gas reduction, as substitutes and alternatives exist, and there is a wide range of co-benefits from transport policies that reduce GHG, through direct impact on air pollutants, injuries and physical activity.

\subsection{Traffic injuries}

Almost $90 \%$ of the 1-2 million deaths and 20-50 million injuries due to road traffic every year occur in low and middle income countries (Peden et al 2004). Half of such casualties are among adults aged between 15 and 44 years. Road traffic injury (RTI) is already the ninth leading cause of death worldwide and is expected to rise to the third cause of death worldwide.

Pedestrians, cyclists and motorized two and three-wheeler riders are the road users most vulnerable to traffic injury, and have the highest risk of death per km travelled of all transport modes (Peden et al 2004). People aged over 60 years have the highest death rates per 100,000 population than other age groups in low and middle income countries (Peden et al 2002).

The bulk of road users in the middle and low income countries will continue to be pedestrians, cyclists, motorized two- and three-wheeler riders and public transport users. It is essential that transport policies give priority to the safety of these user groups (O'Neill \& Mohan 2002) in order to promote public health and ensure health equity, instead of pursuing policies that have often focussed on the private car user.

The World Report on traffic injury prevention (Peden et al 2004) reviews effective policies and measures to prevent RTI, these include land use and transport policies such as the promotion of high density and mixed use developments where work, residence, and entertainment 
are all nearby, reducing the need for transport (Mohan \& Tiwari 2000); providing shorter and safer routes for vulnerable road users; separating motorized and non-motorized traffic and discouraging private cars from entering city centres or encroaching onto pedestrian space. Encouraging the use of safer modes of travel such as public transport, as well as cycling and walking that pose less risk to others than do motor vehicles are also effective, but in developing countries the quality and safety of public transport services needs to be ensured through regulation and enforcement. Enforcing speed and alcohol limits are among the most effective preventive measures, and so are the enforcement of child restraints, safety belts and helmets among users of two wheelers.

\subsection{Physical activity}

Developing and developed countries face the epidemic of non-communicable diseases (WHO, 2005a). Obesity and lack of physical activity are among its main root causes, and widespread increase in physical activity is one of the key recommendations to reverse that trend.

Cycling and walking for daily activities can bring major health benefits (Andersen et al 2000, Hou et al 2004) - half an hour a day can halve the risk of heart disease which is equivalent to the effect of not smoking. Even if spread over two of three shorter episodes, such physical activity improves functional capacity and can halve the risk of diabetes among adults, obesity, some kinds of cancer, reduced blood pressure and osteoporosis (US Surgeon General Report, 1996). These improvements can benefit $60 \%$ of the world population who do very little physical activity (WHO, 2005b).

A large proportion of trips in urban areas are short, and provide the opportunity for daily exercise. An average time of $15 \mathrm{~min}$ is needed for a $2 \mathrm{~km}$ walk or a $3-5 \mathrm{~km}$ cycling trip. However, the enormous saving on health care costs being provided by high levels of cycling and walking for daily activities in many parts of the world is not recognized. There is now a trend in many cities in emerging economies to adopt transport policies that discourage cycling and walking: these policies are likely to create a substantial health bill in future, especially considering the very high costs of treating a range of chronic diseases caused by physical inactivity.

The risk of accidents is an important deterrent to cycling. To obtain and maintain the levels of cycling and walking needed to protect public health it is essential to guarantee safe cycling and walking avenues. Under road safety conditions such as that found in the United Kingdom since the early 1990 s, the health benefits from cycling were estimated to be 20 -fold greater than the health risks associated with cycling (BMA 1992; Rutter 2005).

The built environment has a key role in the promotion of physical activity and on public health, as demonstrated in recent research. Urban sprawl in USA has been associated with obesity, lack of physical activity and hypertension (Ewing et al 2003). Interventions to promote cycling showed remarkable saving on health care costs (4-5 million Euros) and many health benefits including $20 \%$ reduction in road traffic injuries, $20 \%$ reduction in mortality among 15-49 year olds (Odense Municipality 2004), the cost benefit ratio of 4, 14 and 3 in different Norwegian cities (Saelensminde 2002). First analysis of interventions to promote integrated non-motorized and public transport in Bogota (Colombia), Morogoro (Tanzania) and Delhi in India, show that the benefits were 5 to 20 times greater than the cost (I-ce, 2000).

\subsection{Other health risks}

Other transport-related health risks are also well documented and they include risks from transport-related noise on children's learning abilities and development (Huttenmoser 1995), 
the impact of trunk roads on the spread on communicable diseases such as HIV and AIDS, and the impact of rural roads on the livelihoods of rural populations.

\section{Summary}

A large share of the risk to health from transport occurs in urban areas. Urban dwellers are particularly exposed to such risks as humans and vehicles share the same restricted space. Half the world population already lives in cities. Over the next thirty years this population is expected to double to over five billion, and almost all this growth is in developing countries. Health risks from transport thus constitute a public health problem of the very first order.

There is an unprecedented growth in the number of motor vehicles and traffic volumes in urban areas worldwide. Vehicle distance travelled and vehicle stock is expected grow more in non-OECD countries than in OECD countries ( $76 \%$ vs $33 \%$, and $70 \%$ vs $42 \%$ between the years 1995 and 2010). Most of this increase is in private cars (OECD, 2001).

Transport policies in cities worldwide are designed with private cars in mind. Although the vast majority of the world population may not possess a car in the foreseeable future, they will suffer from traffic congestion, and the health risks from pollution, traffic accidents and barriers to cycling and walking.

Cities in the developing world often have a high proportion of daily trips by walking or bicycle; in Chinese cities around 60\% in the mid-1990s and 40\% in cities of Africa (Kenworthy \& Laube 2002). Urban transport policies discourage non-motorized vehicles but encourage car users creating health inequalities, especially in developing countries. The poor tend to suffer most from transport hazards, as they mostly rely on cycling and walking for transport. Those who live and work on the streets travel longer distances to and from work, and use more hazardous vehicles such as two-wheeler mopeds (Mohan \& Tiwari, 2000).

Unhindered motorization shapes cities and communities (urban sprawl), increases travel distances engendering health risks (physical inactivity, longer exposure to pollutants and risk of injury) triggering further sprawl and motorization. Busy streets have been linked to loss of community cohesion and pose limits to children's development. Children are especially vulnerable to environmental air pollution and injuries, and traffic noise can limit their learning ability.

In addition, urban transport policies overlook the health and security function provided by street vendors, and pedestrians in general, as streets with people are safer from violence and traffic injuries. Small street businesses provide livelihoods and contributes to the health of individuals and their families. Street vendors, other workers and policemen in traffic suffer more from air pollution and are at higher risk from traffic injuries.

\section{What can be done?}

Urban and transport planners hold critical tools for promoting health and reducing many of the health inequalities in present-day urban settings. They need to realize their full potential as public health heroes.

Experience in many cities has shown that healthier transport systems can be developed in relatively short time periods through broadly framed strategies, that consider the full range of key health and development issues. For example, Bogota (Colombia) and Curitiba (Brazil) have well documented and positive experiences of better transport systems. 


\subsection{Key ingredients}

Adopting a public transport vision for health and social equity - providing for the access needs of the majority of the urban population, and considering the health risks from transport should be part of the objectives of the transport sector. The objectives include: (i) linking the leadership and creating practical mechanisms for exchange between transport, urban planning and public health actors; (ii) creating access to knowledge on how a broad range of transport solutions contributes to public health and helps avoid health risk; and knowledge of experience of what worked elsewhere, what didn't and insights into why this may have been so; (iii) carrying out health impact assessments of proposals for land use and transport, to be able to anticipate the expected health consequences of policy options (Dora \& Racioppi 2003).

\subsection{Transport solutions that benefit health}

(a) Transport demand management, compact cities, emphasizing proximity between homes and work/markets/leisure/study places, and reduces the need to travel and exposure to transport-related health risks. (b) Priority to transport modes with least risks to health per unit of travel: low pollution, low injury risk, enhancing physical activity. (c) Priority in urban space should be for public transport, cycling and walking, with connectivity assured between these modes. (d) Protection of vulnerable road users - pedestrians and cyclists should be assured dedicated space and protection in road design. (e) Public transport and urban space should be accessible to all levels of physical ability. (f) Adoption of clean and safe technologies; improvement of vehicle maintenance standards, testing and surveillance of polluting vehicles; enforcement of speed and alcohol-while-driving limits and traffic regulations; and adoption of individual safety measures such as helmets, and seat belts. (g) Internalization of all health-related external costs into the transport decision-making process.

\subsection{Frequent pitfalls}

Experience highlights the limitations of narrowly focussed interventions in delivering the expected health benefits, as several health risks from urban transport are closely related. For example, the impact of technical solutions to reduce air pollution based purely on technology improvements may be quickly cancelled out by the added growth in motor vehicles and increased travel distances (OECD, 2001). The change in health risks from adopting CNG in buses for a city involves substitution for other more polluting means of transport such as two-stroke engines in two-wheelers in view of bus travel getting expensive (Tiwari 2003).

Environmental assessments of transport policies often claim to contribute to health improvements, but systematically overlook the health benefits of physical activity through transport.

There has been a major gap in understanding the contribution of cycling and walking for the transport system and for public health, leading to interventions to curb cycling and pedestrians from the streets on the basis of a belief that rapid transit is the only solution. The role of street vendors, and of non-motorized street users is also largely overlooked by system policies.

\section{Conclusion}

Professionals in urban planning and transport engineering have a key role to play in making the links between planned interventions with health, environment and social impacts, and should not shy away from this broad responsibility. 
Transport-related health impacts and inequalities offer a benchmark against which to measure the achievements of transport interventions on a human scale, a key for communicating and linking with broader constituencies.

The new urban settings need integrated and holistic goals, system-wide solutions, as well as objective and meaningful assessment of results, costs and benefits. A new urban engineering leadership is needed to engage with others in protecting us from cities where the operation was a success but the patient died.

\section{References}

Andersen L B, Schnohr P, Schroll M, Hein H O 2000 All-cause mortality associated with physical activity during leisure time, work, Sports, and Cycling to Work. Arch Intern Med 160: $1621-1628$

Avol E L et al 2001 Respiratory effects of relocating to areas of differing air pollution levels. American Journal of Respiratory and Critical Care Medicine 164: 2067-2072

British Medical Association 1992 Cycling: towards health and safety (Ed.) M Hillman, (Oxford: Oxford University Press)

British Medical Association 1997 Road transport and health. London: BMA

Buringh E et al 2002 On health risks of ambient PM in the Netherlands. Executive summary. Bilthoven, National Institute for Public Health and the Environment (RIVM)

Clancy L et al 2002 Effects of air pollution control on deaths in Dublin, Ireland: an intervention study. Lancet 360: 1210-14

Cohen A J, Anderson H R, Ostro B, Pandey K D, Krzyzanowski M, Künzli N, Gutschmidt K, Pope C A III, Romieu I, Samet J M, Smith K R 2004 Urban air pollution. Comparative quantification of health risks (Eds.) M Ezzati, A D Lopez, A Rodgers, C J L Murray (Geneva: WHO)

Dora C, Racioppi F 2003 Including health in transport policy agendas: the role of health impact assessment analysis and procedures in the European experience. Bulletin of the World Health Organization 81(6): 399-403

EEA 2002 National and central estimates for air emissions from road transport. Technical Report 34 (Copenhagen: European Environment Agency)

Ewing R, Schmid T, Killingsworth R, Zlot A, Raundebush S 2003 Relationship between urban sprawl and physical activity, obesity and morbidity. Am. J. Health Promotion 18(1): 47-57

Hedley A J et al 2002 Cardiorespiratory and all-cause mortality after restrictions on sulfur content of fuels in Hong Kong: an intervention study. Lancet 360: 1646-1652

Hoek $\mathrm{G}$ et al 2002 Association between mortality and indicators of traffic-related air pollution in the Netherlands: a cohort study. Lancet 360(9341): 1203-1209

Hou L, Ji B, Blair A, Dai Q, Gao Y, Chow W 2004 Commuting Physical Activity and Risk of Colon Cancer in Shanghai, China. American Journal of Epidemiology 160(9): 860-867

Huttenmoser M 1995 Children and their living surroundings: empirical investigations into the significance of living surroundings for the everyday life and development of children. Child Environ 12: $403-413$

I-ce, Interface for cycling expertise \& the association of Dutch municipalities VNG, 2000 The economic significance of cycling: a study to illustrate the costs and benefits of cycling policy. (The Hague, Habitat Platform Foundation,. accessed 30 October 2005 at: http://www.ice.info/download/publications/Ec_Significance_eng.pdf)

International Panel on Climate Change - IPCC 2001a. Climate Change 2001. Synthesis Report. (Cambridge: WMO/UNEP)

International Panel on Climate Change - IPCC 2001b Climate Change 2001. Mitigation: Contribution of Working group III to the Third Assessment Report. (Cambridge: Cambridge University Press) 
Kenworthy J, Laube F 2002 Urban Transport patterns in a global sample of cities \& their linkages to transport infrastructures, land use, economics \& environment. World Transport Policy \& Practice 8(3): 5-20

Krzyzanowski M, Kuna-Dibbert B, Schneider J 2005 Health effects of transport-related air pollution. (Copenhagen: World Health Organization Regional Office for Europe)

McMichael A J, Githeko A 2001 Human Health. Climate Change 2001: Impacts, Adaptation and Vulnerability. (McCathy J J, et al Cambridge: Cambridge University Press)

McMichael et al 2004 Climate change. Comparative quantification of health risks: Global and Regional burden of disease due to selected major risk factors. ((Eds.) MEzzati, A Lopez, A Rodgers, C Murray, Geneva: World Health Organization)

Mohan D, Tiwari G 2000 Mobility, Environment and Safety in Megacities: Dealing with a Complex Future. IATSS Research 24(19): 39-46

O'Neill M S et al 2003 Health, wealth and air pollution: advancing theory and methods. Env Health Perspectives 111: 1861-70

Odense Municipality (Odense Kommune) 2004 Evaluering af Odense-Denmark's Nationale Cykelby [Evaluation of Odense, Denmark's national cycle city] (in Danish with English summary). Odense: Odense Municipality.

OECD Environment Outlook 2001 (Paris: Organization for economic cooperation and development)

O'Neill B, Mohan D 2002 Reducing motor vehicle crash deaths and injuries in newly motorising countries. BMJ 324: 1142-1145

Peden $\mathrm{M}$ et al 2004 The world report on road traffic injury prevention. (Geneva: WHO)

Peden M, McGee K, Sharma G 2002 The injury chart book: a graphical overview of the global burden of injuries. (Geneva: WHO)

Pope C A et al 2002 Lung cancer, cardiopulmonary mortality, and long-term exposure to fine particulate matter air pollution. JAMA 287: 1132-1141

Roemer W H, van Wijnen J H 2001 Daily mortality and air pollution along busy streets in Amsterdam, 1987-1998. Epidemiology 12(6): 649-653

Rutter H 2005 Personal communication.

Saelensminde K 2002 Walking and cycling track networks in Norwegian cities - Cost benefit analyses including health effects and external costs of road traffic. TOI report 567 (in Norwegian Oslo: Insititute of transport economics)

Sanderson E et al 2005 Human exposure to transport-related air pollution. Health effects of transportrelated air pollution. ((Eds.) M Krzyzanowski, B Kuna-Dibbert, J Schneider. Copenhagen: World Health Organization Regional Office for Europe)

Schwartz J et al 2002 The concentration-response relationship between PM 2.5 and daily deaths. Environmental Health Perspectives 110(10): 1025-1029

Tiwari G 2003 Transport and land-use policies in Delhi. Bulletin of the World Health Organization 81(6): 444-450

US Surgeon General Report 1996 Physical Activity and Health: A Report of the Surgeon General (Atlanta, Ga: Centres for Disease Control and Prevention)

WHO 2002 World Health Report 2002 - Reducing risks, promoting healthy life. Geneva: World Health Organization (http://www.who.int/whr/2002/, accessed March 2005)

WHO 2005a Prevention and control of non-communicable diseases: implementation of the global strategy. Document EB/20/22 (Geneva: World Health Organization)

WHO 2005b Preventing chronic diseases: A vital investment. (Geneva: World health Organization) 